\title{
Traduções do fantástico de Roald Dahl: um estudo baseado no corpus da obra Charlie and the Chocolate Factory
}

\author{
Talita Serpa" \\ Priscila Taconi Geromini"** \\ Andreia Regia Nogueira do Rego"
}

\section{Resumo}

O presente trabalho analisa a tradução da obra de Roald Dahl, Charlie and the Chocolate Factory (2007), publicada pela primeira vez em 1964, para o Português no que tange ao léxico voltado à Literatura Infantil Fantástica. Para tanto, valemo-nos da Literatura Infantil (COELHO, 1991, 2000), da Literatura Fantástica (TODOROV, 1975; HELD, 1980), bem como salientamos os Estudos do Léxico (BIDERMAN, 1987), a Linguística de Corpus (BERBER SARDINHA, 2000) e os Estudos da Tradução Baseados em Corpus (BAKER, 1993, 1996; CAMARGO, 2005, 2007). Comparamos o texto traduzido (TT) ao texto original (TO) com o auxílio do software WordSmith Tools (SCOTT, 2015), a fim de reconhecer frequência e concordância de itens lexicais presentes na escrita de Dahl, os quais retomam fatores pertinentes ao mundo mágico. Sendo assim, traçamos caminhos para a análise dessa linguagem tanto na Língua Fonte quanto na Língua Meta, salientando o modo como se relacionam na concepção do maravilhoso para o público infantil.

Palavras-chave: Estudos da Tradução Baseados em Corpus. Linguística de Corpus. Literatura Infantil Fantástica. Roald Dahl.
* Doutoranda do Programa de Pós-Graduação em Estudos Linguísticos da Universidade Estadual Paulista. Professora Titular do curso de graduação em Letras, Tradutor e Intérprete, da União das Faculdades dos Grandes Lagos. E-mail: talitasrp82@gmail.com

** Bacharel e licenciada em Letras com habilitação para tradução pela União das Faculdades dos Grandes Lagos. E-mail: prihtaconi@hotmail.com

*** Doutora pelo Programa de Pós-Graduação em Letras (na área de Literatura) da Universidade Estadual Paulista, câmpus de São José do Rio Preto. Coordenadora e Professora Titular do curso de graduação em Letras, Tradutor e Intérprete, da União das Faculdades dos Grandes Lagos. E-mail: letras@unilago.edu.br

Data de submissão: 24/07/2017 - Data de aceite: ago. 2017 http://dx.doi.org/10.5335/rdes.v13i2.7244 


\section{Introdução}

O presente trabalho tem por premissa analisar itens lexicais de maior recorrência em contextos da obra Charlie and the Chocolate Factory (2007), publicado pela primeira vez em 1964, de Road Dahl, bem como em sua respectiva tradução para a Língua Portuguesa, sob o título $A$ Fantástica Fábrica de Chocolate (2014), realizada por Dulce $\mathrm{H}$. Vainer, no ano de 1989.

Esta narrativa, considerada de cunho infantojuvenil, convida-nos a conhecer a história de Charlie, um pobre garoto que vê sua vida mudar a partir da visita ao que podemos considerar um novo mundo, o qual se torna seu objeto de desejo: a fábrica de chocolates Wonka. Dentro deste ambiente, notoriamente mágico, somos guiados, ao longo do percurso, pela figura excêntrica de Willy Wonka, que nos envolve e surpreende com suas invenções e histórias fantasiosas.

A obra, nesse sentido, apresenta um vocabulário rico na temática do fantasioso e, dessa forma, enquadra-se no que Held (1980) chama de Literatura Infantil Fantástica. Por conseguinte, em nossa investigação, retomamos autores como Coelho (1991, 2000), a fim de definir Literatura Infantil e associá-la a características da Literatura Fantástica (TODOROV, 1975). Atrelamos as noções de gênero literário para jovens leitores aos constructos de exploração do imaginário e distanciamento do cotidiano.
No que diz respeito aos itens lexicais e à sua frequência de uso no texto literário em tela, recorremos a autores como Biderman (1987), para quem o léxico de uma língua é a forma de registrar conhecimento e verificações do mundo, assim, quando o homem nomeia os objetos, classifica-os simultaneamente. A Linguística de Corpus (BERBER SARDINHA, 2000), bem como os Estudos da Tradução Baseados em Corpus (BAKER, 1993, 1996; CAMARGO, 2005, 2007), por sua vez, auxiliam-nos na coleta e na exploração do conjunto dos dados linguísticos, a fim de que esses sirvam para a observação das aproximações e dos distanciamentos entre as opções do texto fonte (TF) e do texto meta (TM).

Para o levantamento e a análise dos dados, utilizamos o software WordSmith Tools (versão 6.0) em suas ferramentas WordList e Concord, a fim de proceder a um estudo comparativo, analisando as escolhas linguísticas do autor e da tradutora, associando tais princípios às questões culturais e literárias. Acreditamos que a escrita de Roald Dahl mostra-se rica em um vocabulário de caráter fantasioso, o qual, no plano literário de cunho infantil, tende a auxiliar na formação dos princípios de moralidade e nas desconstruções de representações sociais. Sendo assim, procuramos verificar o processo de composição dessas características no texto original (TO) e no texto traduzido (TT), a fim de traçar considerações sobre tais elementos na Literatura em língua fonte (LF) e língua meta (LM). 


\section{A Literatura Infantil Fantástica}

Em nossa investigação, consideramos que:

A Literatura Infantil é, antes de tudo, literatura; ou melhor, é a arte do fenômeno da criatividade, que representa o mundo, o homem, a vida, através das palavras. Funde os sonhos e a vida prática, o imaginário e o real, os ideais e sua possível/impossível realização [...] (COELHO, 2000, p. 27).

Trata-se de um fenômeno significativo e de fundamental importância na formação das mentes infantis e juvenis, ou seja:

[...] um instrumento de emoções, diversão ou prazer, desempenhado pelas histórias, mitos, lendas, poemas, contos, teatro, etc., criado pela imaginação poética, ao nível da mente infantil, que objetiva a educação integral da criança, propiciando-lhe a educação humanística e ajudando-a na formação de seu próprio estilo (COELHO, 1991, p. 05).

Uma vez que um dos objetivos da Literatura Infantil fundamentou-se como sendo o de divertir, Coelho levanta uma questão que provoca discussões: "o ideal para os pequenos leitores seria a leitura realista? Ou a fantástica?" (2000, p. 51). Como resposta a sua própria pergunta, a autora afirma que, conforme a época, uma ou outra dessas duas formas predomina no ato de criação e no gosto do público, e "nenhuma dessas formas é melhor ou pior, literariamente" (grifo nosso).
Em seus primórdios, a literatura foi essencialmente fantástica: na infância da humanidade, quando os fenômenos da vida natural e as causas e os princípios das coisas eram inexplicáveis pela lógica, o pensamento mágico ou mítico dominava. Ele está presente na imaginação que criou a primeira literatura: a dos mitos, lendas, sagas, cantos rituais, contos maravilhosos, etc. [...] Compreende-se, pois, porque essa literatura arcaica acabou se transformando em literatura infantil: a natureza mágica de sua matéria atrai espontaneamente as crianças (COELHO, 2000, p. 52, grifo da autora).

Essa literatura recheada de elementos mágicos e míticos, cuja essência é fantástica e atrai espontaneamente as crianças para o seu conteúdo, ficou conhecida como Literatura Infantil Fantástica.

Coelho (2000) caracteriza-a como uma duplicidade intrínseca do abstrato - uma vez que é gerada por ideias, sentimentos, emoções e experiências - em associação com o concreto - tendo em vista que essas experiências só são efetivamente encaixadas na realidade quando nomeadas, transformadas em linguagem ou em palavras, que, por sua vez, precisam estar registradas em algo que seja o seu suporte físico, permitindo-lhes que se comuniquem com o seu destinatário e que perdurem no tempo.

Dessa forma, realizamos a associação com as premissas de Todorov, considerando ser preciso verificar que “a expressão 'literatura fantástica' se refere a uma variedade da literatura ou, como se diz normalmente, a um gênero literário" (1975, p. 27) surgido entre os séculos XVIII e XIX. 
Coalla (1994) aponta que tal gênero atravessou diferentes fases durante os séculos: no final do século XVIII e início do XIX, trazia a presença do sobrenatural, com monstros e fantasmas; no século XIX, explorou a dimensão psicológica e substituiu o sobrenatural pela loucura, as alucinações e os pesadelos; já, no século $\mathrm{XX}$, foi transportado para a linguagem e passou a criar a incoerência entre os elementos do cotidiano. Podemos notar que o gênero está sempre evoluindo, mas possui uma característica importante, que está sempre presente: o leitor aceitar os fatos inexplicáveis como se fossem situações reais.

Todorov (1975) considera a essência dessa produção como sendo a irrupção, em nosso mundo, de um acontecimento que não pode ser explicado pelas leis racionais, surgindo a ambiguidade, a incerteza diante de um fato que, aparentemente, é irracional. Essa dúvida causada no leitor resulta no surgimento do fantástico.

O fantástico se ramifica em dois subgêneros: o estranho e o maravilhoso. Uma vez que o fantástico só existe por meio da hesitação, quando o leitor ou $o$ personagem apresenta os fatos inexplicáveis o efeito desaparece, o que deve ocorrer somente no final da narrativa. Se o leitor decide explicar esses fenômenos por meio das leis da realidade, classificando-os como sonho, loucura ou drogas, a obra pertence ao gênero fantástico-estranho; mas, se ele decide que deve admitir novas leis da natureza que explicam o fenômeno, temos o gênero fantástico-maravilhoso.
Por fim, Held (1980), em sua obra $O$ imaginário no poder: as crianças e a literatura fantástica, afirma que o texto literário fantástico no universo infantil trata-se de um objeto estético com o qual as crianças irão interagir e, então, emancipar o seu imaginário para se reencontrar com o lúdico e a criatividade na linguagem.

\section{Roald Dahl e o fantástico}

A chave principal para o sucesso de Dahl é a importância atribuída ao fantástico, argumento que pode ser reforçado por Bruno Bettelheim:

Para que uma estória realmente prenda a atenção da criança, deve entretê-la e despertar sua curiosidade. Mas para enriquecer sua vida, deve estimular-lhe a imaginação: ajudá-la a desenvolver seu intelecto e a tornar claras suas emoções; estar harmonizada com suas ansiedades e aspirações; reconhecer plenamente suas dificuldades e, ao mesmo tempo, sugerir soluções para os problemas que a perturbam. Resumindo, deve de uma só vez relacionar-se com todos os aspectos de sua personalidade - e isso sem nunca menosprezar a criança, buscando dar inteiro crédito a seus predicamentos e, simultaneamente, promovendo a confiança nela mesma e no seu futuro (BETTELHEIM, 2002, p. 05).

De acordo com o autor, as crianças precisam da essência da literatura, pois, por meio dessa, aprendem sobre os seres humanos e sobre o nível simbólico da linguagem. A partir do texto literário, deparam-se com narrativas complexas de desejos realizados que ensinam ao leitor que as dificuldades que encontrarem na vida são intrínsecas à existência, e, por mais complexas que sejam, não se 
deve fugir delas, mas sim encará-las, o que é injusto, tentando ser vitoriosos. Dessa forma, as obras podem ser vistas como uma fantasia poderosa e esperançosa, que os mantém seguindo em frente (BETTELHEIM, 2002).

\section{Tradução e Literatura Fantástica}

Acreditamos, em nossa investigação, que a Literatura Infantil Fantástica, ao ser produto da composição literária adulta e também ao ser vertida para os mais diversos idiomas por adultos, coloca o tradutor em posição de intermediário de uma mensagem que explora o irreal, $o$ metafórico, propiciando ao leitor infantil uma fuga da realidade.

É interessante pensar a Literatura dentro de um sistema engendrado cultural e socialmente, em que a tradução de Literatura Infantil ocuparia uma posição de impacto para a formulação de novas ideologias e novos valores para um público específico, trazendo à baila princípios e leituras novas.

Para Queiroga e Fernandes, em "Translation of children's literature" (2016), há uma grande complexidade no exercício tradutório em Literatura Infantil. Os autores apontam as particularidades da tradução, entre as quais se destacam: a relação assimétrica/leitor dual em que o adulto se interpõe em todas as etapas que compõem a (tradução de) Literatura Infantil; a multiplicidade de funções, dado apontado pela inserção/pertencimento do gênero aos sistemas socioeducacional e literário e permeado de valores por eles atribuídos; e a manipulação textual, percebida nas liberdades tomadas em virtude da condição periférica do gênero.

\section{Os Estudos da Tradução a Lexicologia e a Linguística de Corpus}

O conceito de léxico é descrito por Biderman como:

O léxico de uma língua natural constitui uma forma de registrar o conhecimento do universo. Ao dar nome aos objetos, o homem os classifica simultaneamente. [...] Ao reunir os objetos em grupos, identificando semelhanças e, inversamente, discriminando os traços distintivos que individualizam esses objetos em entidades diferentes, o homem foi estruturando o mundo que o cerca, rotulando essas entidades discriminadas. Foi esse processo de nomeação que gerou o léxico das línguas naturais (1987, p. 81).

A autora ressalta que a geração do léxico se processa por meio de atos de cognição da realidade e de categorização da experiência, transformada em signos linguísticos, as palavras.

O ser humano realiza a associação entre os itens lexicais ${ }^{1}$ e os conceitos que simbolizam os referentes, permitindo o surgimento dos signos linguísticos categorizados, expressos em sistemas classificatórios que, por sua vez, constituem os léxicos das línguas naturais.

Biderman aponta haver um "núcleo lexical [de maior frequência] no interior do léxico de um idioma" o qual transpare- 
ce em qualquer tipo discursivo formulado na língua em questão:

[...] cerca de $80 \%$ de qualquer texto são constituídos pelas 500 palavras mais frequentes da língua, incluindo-se aí um conjunto de palavras de valor semântico muito geral e a totalidade das palavras gramaticais dessas línguas (1987, p. 28).

Por sua vez, no âmbito da Linguística de Corpus, Berber Sardinha (2000) salienta a coleta e a exploração de corpora, ou dos "conjuntos de dados linguísticos textuais coletados criteriosamente, com o propósito de servirem para a pesquisa de uma língua ou variedade linguística" (2000, p. 325).

Corpus é, por conseguinte, definido como:

Um conjunto de dados linguísticos (pertencentes ao uso oral ou escrito da língua, ou a ambos) sistematizados segundo determinados critérios, suficientemente extensos em amplitude e profundidade, de maneira que sejam representativos da totalidade do uso linguístico ou de algum de seus âmbitos, dispostos de tal modo que possam ser processados por computador, com a finalidade de propiciar resultados vários e úteis para a descrição e análise (SANCHEZ, 1995 apud BERBER SARDINHA, 2000, p. 09).

\section{A Linguística de Corpus}

[...] trabalha dentro de um quadro conceitual formado por uma abordagem empirista e uma visão de linguagem como sistema probabilístico; encaixa-se no que pode ser chamado de Linguística Empírica (BERBER SARDINHA, 2000, p. 30). Assim, sua preferência são os dados resultantes da observação da linguagem, favorecendo a sua utilização dentro da prática tradutória no que tange ao levantamento de traços e a formulação de bancos e glossários, etc.
Nas palavras de Berber Sardinha, Baker, por sua vez,

[...] vê o corpus eletrônico como um instrumento revolucionário, que permite enxergar aspectos da linguagem do texto traduzido em particular, de modo muito mais rico e abrangente do que por outros meios (BERBER SARDINHA, 2004, p. 44).

Para Camargo (2005), os corpora fornecem evidências de como as palavras são empregadas, das possibilidades de como traduzir uma determinada palavra ou segmento textual, e abrem outras perspectivas sobre o processo e a natureza da tradução.

Os estudos da tradução baseados em corpus têm contribuído, de forma dinâmica, para os estudos da tradução como um todo, uma vez que os dados podem ser distribuídos e manipulados de vários modos, por meio de métodos e técnicas diferentes de processamento da linguística de corpus utilizando lista de palavras, palavras-chave e concordâncias, que permite ao analista observar ocorrências, compará-las, aceitar ou refutar hipóteses (CAMARGO, 2007, p. 04).

Baker (1993) reconhece a tradução enquanto espaço diferencial, que deve ser privilegiado na cultura de chegada,

[...] considera a tradução como objeto de estudo per se, e elege, como quadro metodológico para a pesquisa, a abordagem da linguística de corpus (CAMARGO, 2007, p. 4, grifo da autora).

A pesquisadora sugere que:

[...] a tarefa mais importante que aguarda a aplicação das técnicas do corpus nos estudos da tradução [...] é a elucidação da natureza do texto traduzido como um evento comunicativo mediado (BAKER, 1993, p. 243). 
Dessa forma, o uso de corpus nos estudos da tradução se faz importante, pois possibilita, dentro do âmbito tradutório, a reflexão de questões analíticas sobre o texto original (TO) e o texto traduzido (TT), bem como ajuda no entendimento de questões como a escolha de determinados itens lexicais, amplia o campo de trabalho do tradutor, fornecendo uma gama de possibilidades até então desconhecidas ou às quais o tradutor poderia simplesmente não recorrer em seu texto. Essa possibilidade não substitui o serviço do tradutor, assim como a tradução automática não faz, mas, aliado aos mecanismos computacionais, o uso dos corpora nas traduções pode melhorar e enriquecer todo o processo.

\section{Metodologia}

A partir do corpus da obra Charlie and the Chocolate Factory (2007), de Dahl, e de sua respectiva tradução para o português A Fantástica Fábrica de Chocolate (2014), realizada por Vainer, analisamos a composição dos elementos mágicos com base no uso do conjunto do léxico de maior frequência.

Inicialmente, realizamos, com o auxílio da ferramenta WordList do software WordSmith Tools (versão 6.0), o levantamento do arcabouço lexical de maior frequência do corpus em questão, selecionando as palavras que fazem parte da composição dos elementos fantástico.

Das listas produzidas, elencamos cinco itens lexicais que remetem ao fantás- tico e se complementam: Wonka, Charlie, Chocolate (factory) Oompa e Loompa, bem como suas traduções "Wonka", "Charlie", "Chocolate" (fábrica), "Umpa" e "Lumpa".

Com base nesses dados, passamos a buscar, utilizando a ferramenta Concord, as palavras selecionadas para análise em seus respectivos contextos de uso, procurando verificar possíveis relações que estabelecem entre si na constituição de elementos fantásticos, na obra de Dahl em Inglês e Português.

\section{Análise dos dados}

A seguir, passamos a analisar as informações do corpus principal de nossa investigação. Na Tabela 1, apresentada a seguir, encontram-se os dez itens mais frequentes no TO.

Tabela 1 - Listagem dos itens lexicais de maior frequência presentes no TO Charlie and the Chocolate Factory, de Roal Dahl

\begin{tabular}{l|c|c}
\hline \multicolumn{1}{c|}{ Palavra } & Frequência & $\%$ \\
\hline Wonka & 297 & 0,95 \\
Charlie & 224 & 0,71 \\
Chocolate & 130 & 0,41 \\
Factory & 77 & 0,25 \\
Oompa & 64 & 0,20 \\
Golden & 55 & 0,18 \\
Gum & 53 & 0,17 \\
Ticket & 53 & 0,17 \\
Children & 52 & 0,17 \\
Boy & 42 & 0,13 \\
\hline
\end{tabular}

Fonte: elaborada pelas autoras. 
Na sequência, a Tabela 2 apresenta os dez itens lexicais de maior frequência no TT.

Tabela 2 - Listagem dos itens lexicais de maior frequência presentes no TT $A$ Fantástica Fábrica de Chocolate, por Dulce H. Vainer

\begin{tabular}{l|c|c}
\hline \multicolumn{1}{c|}{ Palavra } & Frequência & $\mathbf{\%}$ \\
\hline Wonka & 302 & 1,13 \\
Charlie & 242 & 0,91 \\
Chocolate & 150 & 0,56 \\
Fábrica & 81 & 0,30 \\
Cupom & 62 & 0,23 \\
Umpa & 62 & 0,23 \\
Chicletes & 48 & 0,18 \\
Crianças & 45 & 0,17 \\
Lumpas & 42 & 0,16 \\
Elevador & 41 & 0,15 \\
\hline
\end{tabular}

Fonte: elaborada pelas autoras.

Em primeira instância, podemos perceber que Wonka, o personagem principal, que traz toda a magia para a história, foi mantido como o item de maior frequência nas duas obras, tendo sido utilizado mais vezes no TT do que no TO (297 ocorrências no TO e 302 ocorrências no TT).

O mesmo ocorre com Charlie, o herói da história, (frequência de 224 vezes no TO e de 242 no TT), com chocolate (frequência de 130 vezes no TO e de 150 no TT) e com factory (77 ocorrências), o lugar em que a fantasia da obra acontece, e "fábrica" (81 ocorrências).

Seguindo esses dados, iniciamos a seleção dos fatores a serem explorados, levando em consideração o gênero literário do corpus de estudo: a Literatura Infantil Fantástica.
Conforme ressaltamos no primeiro capítulo, Coelho (2000) afirma que essa matéria literária, a Literatura Infantil Fantástica, caracteriza-se pela duplicidade do abstrato associado ao concreto, dessa forma, temos ideias, sentimentos, emoções e experiências acontecendo em nossa realidade, assim, transformando-se em linguagem e em palavras, que são transmitidas em um suporte físico. Isso é o que o TO e o TT fazem: o mundo real existe e, para alguns, como o personagem principal Charlie, chega a ser cruel, mas, dentro da fábrica de chocolates e com a figura de Willy Wonka, tudo aquilo que o menino sonha, todas as suas ideias acontecem de fato; e, por meio do suporte linguístico, o livro transporta os leitores para um novo mundo em que a fantasia cria aquilo que existe somente no imaginário, na realidade dos personagens, distanciando-se totalmente do cotidiano e levando os leitores a explorarem um ambiente novo e desconhecido.

\section{Wonka}

Willy Wonka é o dono da fábrica de chocolate, e, com isso, toda a magia existente no livro é originária de suas ideias e criações. Uma vez que o fantástico consiste no escape do mundo real para o imaginário, Wonka é quem cria o mundo em que essa fuga acontece, o personagem é a própria Fantasia, tornando-se, assim, $o$ item lexical mais frequentemente utilizado. Com a finalidade de comprovarmos esse argumento, selecionamos dois 
trechos de exemplos em que o vocábulo Wonka é encontrado no corpus do TO, como apresentado no quadro a seguir:

Quadro 1 - Trechos com a palavra Wonka no TO

'Come to bed, my darling,' said Charlie's mother.

'Tomorrow's your birthday, don't forget that, so I expected you'll be up early to open your present'. 'A Wonka chocolate bar!' cried Charlie. 'It is a Wonka bar, isn't it?' 'Yes, my love,' his mother said. 'Of course it is.'

'Choose a button!' said Mr. Wonka. 'The two children may press one button each. So take your pick! Hurry up! In every room, something delicious and wonderful is being made.'

Fonte: elaborado pelas autoras.

No primeiro excerto, temos um diálogo do personagem Charlie com sua mãe sobre qual será seu presente de aniversário: uma barra de chocolate Wonka. Nesse caso, a palavraWonka não se refere ao personagem Willy Wonka, mas sim ao produto de sua fábrica, uma barra de chocolate. Essa barra de chocolate poderia ser comum para a maioria das pessoas, mas não para Charlie, pois uma vez que as condições financeiras de sua família eram precárias, o menino passava $o$ ano todo sonhando/fantasiando com os chocolates Wonka e ganhava esse presente uma única vez, em seu aniversário. Se Wonka não está presente para ser o fantástico, ele propicia com suas criações um momento maravilhoso no cotidiano.

Já no segundo trecho, temos uma fala de Willy Wonka para as crianças durante a visita na fábrica: Wonka explica que cada criança tem direito a apertar um botão do elevador que leva para uma das salas, onde algo delicioso e maravilhoso está sendo feito, e elas devem fazer suas escolhas rápido. Os personagens estão dentro do gigantesco elevador que os leva para qualquer lugar na fábrica, e o uso dos adjetivos delicious e wonderful na oração ilustra a imagem que construímos, ao longo da história, do lugar: delicioso e maravilhoso. A seguir, trazemos os excertos que correspondem a esses trechos no TT:

Quadro 2 - Trechos com a palavra "Wonka" no TT

- Hora de ir para a cama, filho - disse a mãe de Charlie. - Amanhã é seu aniversário, não esqueça, acorde cedinho para abrir o presente.

- Um tablete de chocolate Wonka! É chocolate Wonka, não é? - exclamou Charlie.

-É sim, meu filho. Claro que é!

- Escolha um botão. Cada uma das crianças pode escolher dois botões. Escolham. Depressa! Em cada sala há alguma coisa deliciosa e maravilhosa sendo feita.

Fonte: elaborado pelas autoras.

É visível, nos dois trechos, que a tradutora manteve-se próxima à ideia dos diálogos e às escolhas dos itens lexicais com relação à obra original, mas optou por deixá-los mais dinâmicos, tornando a leitura fluída, como, por exemplo: no primeiro trecho manteve-se o uso de "Wonka", assim como no TO, pois tal fator não afeta a leitura, ao contrário, intensifica a animação do garoto com o presente. A tradutora também modificou somente o início do trecho, uma vez que há, no TO, o uso das expressões said 
Charlie's mother e his mother said, enquanto, na tradução, temos um diálogo sequencial entre mãe e filho, evitando a repetição.

No segundo excerto, não temos o uso de "Wonka", pois, como se trata de um diálogo entre "Willy" e os visitantes, há uma sequência nas falas; e essa identi- ficação é realizada no trecho precedente, subentendendo-se, assim, que o dono da fábrica é quem está falando.

Ao analisarmos um terceiro exemplo, tanto do TO, quanto do TT, temos a descrição física do personagem Wonka, a imagem que as crianças criam em seus subconscientes:

\section{Quadro 3 - Trecho sobre o personagem Wonka no TO e no TT}

Mr. Wonka was standing all alone just inside the open gates of the factory. And what an extraordinary little man he was!

He had a black top hat on his head.

He wore a tail coat made of beautiful plum-colored velvet.

His trousers were bottle green.

His gloves were pearly grey.

And in one hand he carried a fine gold-topped walking cane.

Covering his chin, there was a small, neat, pointed black beard - a goatee. And his eyes - his eyes were most marvelously bright. They seemed to be sparkling and twinkling at you all the time. The whole face, in fact, was alight with fun and laughter.

And oh, how clever he looked! How quick and sharp and full of life! He kept making quick jerky little movements with his head, cocking it this way and that, and taking everything in with those bright twinkling eyes. He was like a squirrel in the quickness of his movements, like a quick clever old squirrel from the park.

Sr. Wonka estava ali, sozinho, do lado de dentro dos portões abertos da fábrica. Era um homenzinho incrível! Na cabeça, uma cartola preta.

Estava com um belo fraque de veludo cor de ameixa.

Suas calças eram verde-garrafa.

Suas luvas eram cinza-pérola.

E, numa das mãos, segurava uma bengala com castão de ouro.

Cobrindo o queixo, tinha uma barbicha preta e pontuda - um cavanhaque. Seus olhos - seus olhos eram incrivelmente brilhantes. Pareciam estar o tempo todo faiscando e cintilando para as pessoas. De fato, todo o rosto dele era iluminado de alegria e felicidade.

E como parecia esperto! Era rápido, decidido e cheio de vida! Começou a fazer movimentos rápidos com a cabeça, balançando-a de um lado para outro, observando tudo com aqueles olhinhos brilhantes. Com aqueles movimentos rápidos parecia um esquilo, um daqueles velhos esquilos ágeis e espertos do parque.

Fonte: elaborado pelas autoras.

Vimos que a Literatura Infantil Fantástica propicia a fuga para o imaginário e, com esse propósito, Dahl criou a figura de Willy Wonka. Ao analisarmos o personagem, podemos perceber que todos os elementos foram criados com a finalidade de fazer dele o porta voz da fantasia, quem faz tudo acontecer. Seu nome, na realidade, é Willian, assim como o de seu pai, mas, por ter fugido de casa e sempre 
ter sentido medo da figura paterna, o personagem adota o apelido Willy, o que, além de mostrar a recusa em aceitar o nome completo, demonstra o seu lado infantil, que se nega a envelhecer. Podemos comprovar esse pensamento com o início do trecho, em que o narrador afirma que Wonka era extraordinary little man, no TO, e, no TT, diz que ele era um "homenzinho incrível". O uso da adjetivação e do diminutivo, nos dois casos, caracteriza o personagem como sendo pequeno, o que, unido ao nome, torna-o quase uma criança, o que ajuda a construir sua personalidade extraordinária, incrível, mítica e mágica.

Na sequência, temos a descrição de seu vestuário, em que a escolha dos substantivos que compõem a sua figura reafirmam sua excentricidade: Wonka usava uma cartola preta, um terno de veludo cor de ameixa, calças verdes e luvas cinzas peroladas, além de carregar uma bengala com a parte superior, o castão, dourado. A mistura de cores, que podemos considerar como extravagância, demonstra sua personalidade e faz as crianças prestarem atenção em sua figura. Além da sua caracterização e de seus olhos brilhantes, ele era alegre, transmitia felicidade, era rápido, ágil e cheio de vida, comportamentos normalmente atípicos em adultos.

Se a Literatura Infantil é destinada aos pequenos leitores, Wonka, o Willy que nunca cresceu, é quem chama a atenção dos leitores dessa literatura; se o fantástico precisa de elementos que fujam do real, saiam do cotidiano, Wonka é um desses elementos. Por mais que ele possa parecer estranho, torna-se um estranho que cativa com seu jeito estapafúrdio e suas ideias malucas. Une seu nome e sua caracterização física juntamente com suas características psicológicas e convida-nos a entrar em seu mundo particular. Sendo assim, somos levados a viver a fantasia da obra, com sua figura nos guiando ao longo dessa viagem.

\section{Charlie}

Charlie é o herói da história. Sua família vive em condições precárias, e ele nunca reclama de nenhum dos problemas, sempre se adapta a todas as situações, suas melhores conversas com os seus avós são sobre a fábrica de chocolate do Sr. Wonka, e seu presente de aniversário é sempre uma barra de chocolate. Com a sorte do destino, encontra uma moeda e consegue o último cupom dourado para visitar o tão sonhado lugar. Enquanto todas as crianças arrumam problemas ao longo da visita, devidos às atitudes que refletem os seus comportamentos, Charlie é o último que resta e, como gratificação por seu bom comportamento e coração, herda a fábrica do Sr. Wonka.

Assim, Charlie torna-se o segundo item lexical mais frequente na obra. Enquanto podemos analisar Wonka como o criador do fantástico, temos em Charlie a criança comum que vivencia e recebe os itens do imaginário, como podemos ver no Quadro 4. 
Quadro 4 - Trechos com a palavra Charlie no TO

Only once a year, on his birthday, did Charlie Bucket ever get to taste a bit of chocolate. The whole family saved up their money for that special occasion, and when the great day arrived, Charlie was always presented with one small chocolate bar to eat all by himself. And each time he received it, on those marvelous birthday mornings, he would place it carefully in a small wooden box that he owned, and treasure it as though it were a bar of solid gold; and for the next few days, he would allow himself only to look at it, but never to touch it. Then at last, when he could stand it no longer, he would peel back a tiny bit of the paper wrapping at one corner to expose a tiny bit of chocolate, and then he would take a tiny nibble - just enough to allow the lovely sweet taste to spread out slowly over his tongue. The next day, he would take another tiny nibble, and so on, and so on. And in this way, Charlie would make his sixpenny bar of birthday chocolate last him for more than a month.

Fonte: elaborado pelas autoras.

Podemos perceber, no excerto, que o pequeno Charlie tinha uma vida difícil e que o chocolate já era, para ele, um escape de seu cotidiano, tendo em vista que era algo a que ele tinha acesso apenas uma vez ao ano e que conseguia fazer uma pequena barrinha de chocolate durar mais que um mês.

Quando verificamos o "papel" da Literatura no universo infantil, notamos que, até certo ponto, ela auxilia o leitor (criança) a realizar as associações de sua realidade com o mundo da ficção, experienciando vivências que não seriam talvez plausíveis em sua história. Isso auxilia o leitor a categorizar valores sociais, a refletir sobre suas ações e consequências. Charlie é, por conseguinte, aquele que direciona a leitura, a visão pela qual a criança irá seguir a narrativa.
Salientamos, também, que entre as escolhas da tradutora em relação aos nomes dos personagens, GrandPa Joe se tornou "vovô José", Oompa-Loompas transformaram-se em "Umpa-Lumpas". Assim, Vainer fez com os demais nomes da obra, tanto dos adultos quanto das crianças, exceto com Willy Wonka e Charlie Bucket.

Acreditamos que a opção por manter o nome das personagens principais é parte do processo de sua construção. Willy Wonka continua "Willy Wonka", porque ele é excepcional e seu nome faz parte de sua caracterização; já Charlie não é traduzido nem modificado exatamente pelo fato de ser diferente das outras crianças. Sendo assim, em Língua Portuguesa, parece-nos que esses personagens assumem ainda mais seus papéis dentro do constructo da ilusão. Há também a questão do sentido implícito nos nomes dos outros personagens, o qual é possivelmente mantido pelas opções de tradução do TT.

Dahl cria em Charlie um modelo com o qual a maioria das crianças pode se identificar, por seus sonhos, por seus desejos, por sua paixão pelo chocolate. Seu bom comportamento e sua educação servem também como uma lição de moral implícita do autor: se as crianças forem como qualquer um dos outros personagens infantis da história, ou seja, mal-educadas, mimadas, gulosas, egoístas, não conseguirão chegar, sequer, ao final da visita; somente com a bondade de coração de Charlie poderão vencer, como o próprio Willy Wonka afirma: 
Quadro 5 - Trecho sobre o personagem Charlie no TO e no TT

'Listen,' Mr. Wonka said, I'I'm an old man. I'm much older than you think. I can't go on forever. I've got no children of my own, no family at all. So who is going to run the factory when I get too old to do it myself? Someone's got to keep it going - if only for the sake of the Oompa-Loompas. Mind you, there are thousands of clever men who would give anything for the chance to come in and take over from me, but I don't want that sort of person. I don't want a grown-up person at all. A grown-up won't listen to me; he won't learn. He will try to do things his own way and not mine. So I have to have a child. I want a good sensible loving child, one to whom I can tell all my most precious sweet-making secrets - while I am still alive.'

- Escute - replicou o Sr. Wonka -, já sou um homem velho. Muito mais velho do que vocês imaginam. Não vou viver para sempre. Não tenho filhos nem família.

Quem vai tomar conta da fábrica quando eu não conseguir mais fazê-lo? Alguém tem que mantê-la, nem que seja só pelos umpa-lumpas. É claro que há milhares de homens inteligentes que dariam tudo para ficar com a fábrica, mas não quero esse tipo de pessoa. Não quero um adulto, que não me escutaria, não aprenderia nada e iria fazer as coisas do jeito dele e não do meu. Prefiro uma criança. Uma criança boa, sensata, carinhosa, a quem eu possa contar todos os meus segredos mais doces e preciosos, enquanto ainda estiver vivo.

Fonte: elaborado pelas autoras.

Wonka buscava uma good sensible loving child, ou seja, "uma criança boa, sensata, carinhosa" [tradução nossa] e encontra tudo isso em Charlie. O personagem infantil é fundamental para a construção da história e a inserção desta no gênero Literatura Infantil Fantástica. Se o fantástico consiste em sair do cotidiano e ir para o patamar imaginário, Charlie experimenta esse imaginário e leva-nos junto consigo para essa aventura; tem, ao decorrer do livro, pensamentos e questionamentos que coincidem com os dos leitores. Ao fim, o personagem deixa de ser o pobre Charlie Bucket, para se tornar o sucessor de Willy Wonka, e mostra às crianças que, a partir de bondade, sensatez, sensibilidade e carinho, elas podem conseguir coisas inimagináveis e mudar toda a sua história de vida.

\section{Chocolate/Factory}

A partir dos usos de chocolate e factory ao longo do corpus do TO, podemos analisar os itens separados e unificadamente.

Chocolate ocorre 130 vezes na $\mathrm{TO}$, o que representa $0,41 \%$ da carga lexical da obra, podendo ser considerado como o substantivo sobre o qual todo o texto se constrói, resultando em um universo fantástico, visto que o que leva Charlie à fábrica de Wonka é a sua paixão pelo doce; e o que faz a fábrica funcionar e acontecer com toda a magia dentro dela é o fascínio de Wonka também pelo doce. Podemos ver os exemplos do uso de chocolate no quadro abaixo: 
Quadro 6-Trechos com a palavra chocolate no TO

Walking to school in the mornings, Charlie could see great slabs of chocolate piled up high in the shop windows, and he would stop and stare and press his nose against the glass, his mouth watering like mad. Many times a day, he would see other children taking bars of creamy chocolate out of their pockets and munching them greedily, and that, of course, was pure torture.

'There!' cried Mr. Wonka, dancing up and down and pointing his gold-topped cane at the great brown river. 'It's all chocolate! Every drop of that river is hot melted chocolate of the finest quality. The very finest quality. There's enough chocolate in there to fill every bathtub in the entire country! And all the swimming pools as well! Isn't it terrific? And just look at my pipes! They suck up the chocolate and carry it away to all the other rooms in the factory where it is needed! Thousands of gallons an hour, my dear children! Thousands and thousands of gallons!'

Fonte: elaborado pelas autoras.

Assim como Charlie amava chocolate, podemos ver o fascínio do Willy Wonka pela guloseima no trecho em que ele descreve uma área de sua fábrica: dançando com a sua bengala, expunha para as crianças o que estava ao seu redor, de um lado, o enorme rio marrom, em que cada gota era feita de chocolate derretido da melhor qualidade. Esse rio daria para encher cada banheira em todo o país e todas as piscinas, o que para ele era fantástico.

Nos dois excertos anteriores, vemos o chocolate como o elemento central do fantasioso, uma vez que Wonka cria um novo mundo repleto de mágica, e Charlie entra nesse mundo novo e leva-nos junto em sua viagem. Se o chocolate nos abre as portas para um universo, temos, na escolha do vocábulo factory a criação desse novo lugar repleto de encanto. O vocábulo ocorre 77 vezes na obra, o que representa $0,21 \%$ de sua carga lexical.

Nesses dados, podemos perceber que factory foi usada principalmente com chocolate e Wonka's, em que ambas unificam dois itens já analisados anteriormente e designam o ambiente em que a fantasia e a magia da obra ocorrem: a fábrica de chocolate Wonka, como pode ser exemplificado no quadro seguinte, que une os dois casos:

Quadro 7 - Trecho com os termos chocolate e factory no TO

And it wasn't simply an ordinary enormous chocolate factory, either. It was the largest and most famous in the whole world! It was WONKA'S FACTORY, owned by a man called Mr. Willy Wonka, the greatest inventor and maker of chocolates that there has ever been. And what a tremendous, marvelous place it was! It had huge iron gates leading into it, and a high wall surrounding it, and smoke belching from its chimneys, and strange whizzing sounds coming from deep inside it. And outside the walls, for half a mile around in every direction, the air was scented with the heavy rich smell of melting chocolate!

Fonte: elaborado pelas autoras.

O narrador nos explica que aquela não era só uma grande manufatura como as outras, aquela era a fábrica de chocolate Wonka, pertencente a um homem chamado Willy Wonka, o maior inventor e fabricante de chocolates que já existiu. Além disso, era um lugar enorme e maravilhoso. Tinha portões de ferro, um muro que cercava todo o seu redor; soltava fumaça de suas chaminés; havia uns zumbidos estranhos que vinham de dentro dela; e, fora das paredes, por 
mais de meia milha ao seu redor, o ar de todas as direções era perfumado com um intenso cheiro de chocolate derretido.

Nesse momento da obra, somos apresentados àquele que será o futuro destino fantástico de Charlie, a fábrica Wonka, e que nos proporcionará o escape de um mundo cotidiano para outro, rico em detalhes. Parece-nos que, no âmbito do fantástico, a própria fábrica ganha características mágicas, chegando mesmo a assumir uma identidade como entidade dentro da cidade. É a fábrica que move a economia daquela sociedade, mas não somente isso, ela constitui as identificações de todas as pessoas da cidade, compõe as relações e os sentidos das existências dos indivíduos e, mesmo, dita a forma como a estrutura urbana se irradia a seu redor, como um ser vivo.

No TT, a palavra "chocolate" foi utilizada 150 vezes, $0,56 \%$ da carga léxica da obra e, ao compararmos com o uso no TO, 130 vezes, percebemos que Dulce $H$. Vainer utilizou a palavra 20 vezes mais. Assim, no próximo quadro, vemos um dos casos em que o mesmo item lexical aparece mais vezes no TT do que no TO:

\section{Quadro 8 - Trecho com a palavra chocolate no} TO e no TT

Mr. Gloop was absolutely right. For suddenly there was a shriek, and then a splash, and into the river went Augustus Gloop, and in one second he had disappeared under the brown surface.

Sr. Glupe tinha razão. Na mesma hora escutaram um guincho, depois um ploft, e lá se foi Augusto Glupe para dentro do rio, e em um segundo tinha afundado no chocolate.

Fonte: elaborado pelas autoras.
Nesses dois exemplos, podemos ressaltar dois pontos: 0 nome do personagem que aparece na oração e a alteração no final da frase que proporciona a inserção da palavra "chocolate". Como falamos no tópico anterior, Dulce H. Vainer traduziu o nome dos personagens a partir de dois aspectos, utilizando nomes que fossem conhecidos ao seu público-alvo e transformando o som da pronúncia do nome, no TO, na escrita do TT, e podemos ver essas duas situações elencadas nesse trecho: primeiro Mr. Gloop se torna Sr. "Glupe" e, depois, Augustus Gloop se torna "Augusto Glupe"; o sobrenome dos personagens, por mais que tenham grafias diferentes, são sonoramente iguais, e o nome do garoto deixa de ser estrangeiro, Augustus, e torna-se brasileiro, "Augusto". O segundo elemento que podemos ressaltar nesse trecho é a escolha de palavras que a tradutora faz no segundo período da oração: and in one second he had disappeared under the brown surfasse, Roald Dahl escreveu que, em um segundo, ele (Augustus Gloop) tinha desaparecido debaixo da superfície marrom, e a tradutora prefere dizer que "e em um segundo tinha afundado no chocolate". Nos dois casos, temos o uso do verbo no presente perfeito, mas, em vez de falar que o garoto havia "desaparecido" debaixo da "superfície marrom" - o rio de chocolate -, a tradutora prefere facilitar o processo de leitura e dizer que o garoto havia "afundado" no "chocolate", simplificando para o seu leitor. 
A palavra "fábrica", por sua vez, não sofreu grandes alterações ao longo da obra e, enquanto no TO foi utilizada 77 vezes, no TT foi utilizada 81 vezes, o que representa $0,30 \%$ da carga lexical, e, ao buscarmos, com o auxílio da ferramenta Concord, as combinatórias do TT, chegamos ao mesmo ponto: a fantástica fábrica de chocolate Wonka.

Assim como no TO, o item "fábrica" é acompanhado de Wonka e chocolate, mas, no caso do TT, temos um termo adicional: fantástica. Podemos entender o uso do adjetivo como objeto de caracterização do ambiente, uma vez que a fábrica de chocolate Wonka é fantástica e é o local em que toda a fantasia acontece, por isso unificamos os dois itens lexicais em nossa análise, como podemos ver no quadro seguinte:

Quadro 9 - Trecho com os termos "fábrica" e "chocolate" no TT

E não era só uma fábrica de chocolate imensa como as outras. Era a FÁBRICA WONKA, que pertencia a um homem chamado Willy Wonka, o maior inventor e fabricante de chocolates que jamais existiu. Era uma fábrica magnífica, maravilhosa! Tinha enormes portões de ferro, era toda cercada por um muro gigantesco, soltava nuvens de fumaça pelas chaminés, e zumbidos estranhos saíam de dentro dela. Um cheiro forte e delicioso de chocolate derretido se espalhava por todos os lados, a muitos quilômetros além de seus muros!

Fonte: elaborado pelas autoras.

Ao longo do texto, dificilmente "fábrica” é um item utilizado sozinho, justamente pelo ambiente não se tratar de um local simples ou comum. Como ve- mos nesse trecho, a fábrica de chocolate Wonka era "magnífica", "maravilhosa" e o portal para um novo mundo, pois, uma vez que a obra se destina aos pequenos leitores e tem como finalidade distanciá-los do cotidiano, eles podem encontrar nessa fábrica todos os seus maiores desejos em forma de doces: rio de calda de chocolate quente, quebra-queixos que duram para sempre, a televisão que consegue transferir um tablete de chocolate de um lugar para outro e todas as outras invenções de Willy Wonka que mexem com o imaginário infantil.

Descobrimos que Roald Dahl era um apaixonado por chocolate ao levantarmos seus dados biográficos e, por isso, orquestrou todos os elementos de sua obra com maestria, a fim de que pudesse convencer e conquistar todos os tipos de leitores, sendo eles crianças ou adultos: fez de Willy Wonka um guia convincente, transformou Charlie em uma criança cativante e fez com que seus leitores acreditassem que todos os desejos poderiam ser encontrados no interior da fábrica, distanciando o cotidiano com um ambiente que, de fato, pode existir, afinal, fábricas de chocolate existem no mundo todo, mas que se transforma em um ambiente mágico a partir de criações e invenções de Wonka, inexistentes na vida real, e que se complementa com a magia dos funcionários, os Oompa-Loompas. 


\section{Oompa/Loompa}

Na sequência dos itens lexicais mais frequentes ocorridos no TO, levantados com o auxílio das ferramentas WordList e KeyWords, do WordSmith Tools, temos Oompa com 62 usos. No entanto, como Oompa é o nome que Roald Dahl deu para suas criaturinhas fictícias, temos a criação, também, de um nome composto: Oompa-Loompa, o qual pode ser flexionado em Oompa-Loompas, quando esses aparecem em grupos. Loompas, como também visto na lista anterior, ocorreu 42 vezes na obra original, o que representa $0,13 \%$ da obra, enquanto Loompa ocorreu 21 vezes, somente $0,07 \%$ da obra, e, unindo os dois usos, temos a mesma frequência de Oompa.

Os Oompa-Loompas são os pequenos seres que trabalham para Wonka na fábrica e que, a fim de alimentarem a fantasia da obra, foram importados diretamente de Loompaland e falam o seu próprio idioma, o Oompa-Loompish. Se o chocolate é o objeto de fascínio, Wonka é o criador da fantasia, e a fábrica é onde a magia acontece, os Oompa-Loompas são os ajudantes de Wonka em toda essa missão e trazem as lições de moral sobre o mau comportamento das crianças, presentes na grande maioria das histórias infantis, conforme apontado por Coelho (2000).

A teoria voltada à Literatura Infantil aponta que o uso desse tipo de texto com os jovens leitores não somente favorece uma função "pedagógica”, mas vai muito além, entrando no universo da formação da moralidade e do conhecimento de mundo da criança, permitindo que ela faça conexões entre a realidade e a ficção e compreenda possíveis relações e ensinamentos que estão por trás de cada composição textual.

No quadro seguinte há o uso tanto de Oompa-Loompa quanto de Oompa-Loompas, assim como um pouco da história e a descrição desses personagens:

Quadro 10 - Trechos com os termos Oompa-Loompa(s) no TO

[...] And they were living on green caterpillars, and the caterpillars tasted revolting, and the Oompa-Loompas spent every moment of their days climbing through the treetops looking for other things to mash up with the caterpillars to make them taste better - red beetles, for instance, and eucalyptus leaves, and the bark of the bong-bong tree, all of them beastly, but not quite so beastly as the caterpillars. Poor little Oompa-Loompas! The one food that they longed for more than any other was the cacao bean. But they couldn't get it. An Oompa-Loompa was lucky if he found three or four cacao beans a year. But oh, how they craved them. They used to dream about cacao beans all night and talk about them all day. [...]

The Oompa-Loompa bowed and smiled, showing beautiful white teeth. His skin was rosy-white, his long hair was golden-brown, and the top of his head came just above the height of Mr. Wonka's knee. He wore the usual deerskin slung over his shoulder.

Fonte: elaborado pelas autoras.

No primeiro excerto, Willy Wonka está contando sobre como encontrou esses pequeninos no lugar em que moravam, 
Loompaland: eles se alimentavam de lagartas verdes, que tinham um gosto horrível, e, assim, os Oompa-Loompas passavam o dia vasculhando a copa das árvores em busca de alguma outra coisa para misturar com as lagartas, a fim de que ficassem com um gosto um pouco melhor. Mas, se tinha uma comida que eles desejavam mais do que qualquer coisa, eram as sementes de cacau, muito difíceis de encontrar. Um Oompa-Loompa ficava satisfeito se conseguisse achar de três a quatro sementes de cacau por ano. Assim, eles sonhavam com as sementes e falavam sobre elas o dia todo.

No segundo trecho, temos uma descrição física do Oompa-Loompa que, após ser chamado por Wonka, faz uma reverência e sorri, mostrando os seus dentes brancos. Sua pele era cor-de-rosa clara, seus longos cabelos eram castanho-dourado e sua cabeça ficava na altura dos joelhos do Sr. Wonka. Além disso, o Oompa-Loompa tinha uma pele de veado pendura no ombro.

Para sua tradução, Dulce H. Vainer optou por transformar Oompa-Loompa em "Umpa-Lumpa", escolheu alterar a grafia do nome dos personagens, mas manteve a sonoridade da nomenclatura, transportando o som do inglês para a grafia em português, assim como mencionamos anteriormente que a tradutora fez com os demais nomes ao longo da obra. Dessa forma, por se tratar da construção de um nome composto, analisamos os dois vocábulos juntos, assim como em relação ao TO.
De todos os itens analisados até o momento, os presentes neste tópico são os únicos cuja frequência é a mesma nas duas obras: "Umpa" foi utilizado 62 vezes, $0,23 \%$ da carga lexical do TT, "Lumpas", 42 vezes $(0,16 \%)$ e o singular, "Lumpa", 19 vezes $(0,07 \%)$. Podemos ver essas semelhanças nos dois trechos do quadro anterior, mas, neste caso, foram retirados do corpus da obra traduzida, A Fantástica Fábrica de Chocolate (2014):

Quadro 11 - Trechos com os termos "Umpa-Lumpa(s)" no TT

[...] Os umpa-lumpas alimentavam-se de lagartas verdes, que têm um gosto horrível, e eles passavam o dia todo vasculhando as copas das árvores procurando alguma outra coisa para misturar com as lagartas, para elas ficarem com um gostinho um pouco melhor - por exemplo, besouros vermelhos, folhas de eucaliptos, e cascas de certas árvores, tudo muito ruim, mas não tão ruim quanto as lagartas. Coitadinhos dos umpa-lumpas! A comida que eles mais desejavam eram sementes de cacau. Mas não conseguiam encontrar! Um umpa-lumpa dava-se por satisfeito se conseguisse achar três ou quatro sementes de cacau por ano. E era a coisa que mais almejavam! Sonhavam com cacau a noite toda e durante o dia só falavam em cacau [...]

O umpa-lumpa fez uma reverência e sorriu, mostrando seus dentes lindos, branquinhos. Sua pele era cor-de-rosa clara, seus cabelos castanhos dourados e sua cabeça chegava bem na altura dos joelhos do Sr. Wonka. Usava uma pele de veado sobre os ombros.

Fonte: elaborado pelas autoras.

Verificamos que, nos dois excertos, a tradutora manteve o TT próximo, em grande parte, ao TO, mas realizou duas alterações. No primeiro trecho, no TO, Roald Dahl havia escrito que 
os personagens procuravam por cascas de bong-bong tree, o que podemos considerar como um tipo específico de árvore que também foi criada pelo autor; já Dulce H. Vainer opta por dizer que procuravam pelas cascas de "certas árvores", sem especificar quais. Outro detalhe importante que podemos ressaltar e que está presente nos dois trechos é a escolha da tradutora também em relação à sua tradução de Oompa-Loompas: na obra original, tanto no singular quanto no plural, os termos são escritos com as iniciais maiúsculas, indicando que este é o nome dos personagens; já na tradução, temos "umpa-lumpas", com as iniciais minúsculas, o que resulta no entendimento de que, enquanto no TO esse é o nome dos personagens, no TT, trata-se do nome não dos personagens, mas da espécie deles, que, consequentemente, serve para nomeá-los.

Como a obra trata-se de Literatura Infantil Fantástica, Roald Dahl cria essas criaturas com a finalidade de complementarem as duas características principais do gênero que viemos destacando ao longo do trabalho: são criaturas inexistentes, mas que, naquele contexto, não possuem sua existência questionada pelas crianças, exatamente pelo fato de pertencerem e completarem aquele ambiente mágico e fantasioso. Não é preciso explicar, eles existem e elevam a obra a um patamar ainda mais distante da realidade, uma vez que a existência dos personagens é confirmada, eles tornam as morais, características das histórias infantis, explícitas, utilizando suas canções para falarem sobre o mau comportamento das crianças e o resultado deste, como veremos no tópico seguinte.

\section{As canções dos Oompa-Loompas}

Ao longo da obra Charlie and the Chocolate Factory (2007), de Roald Dahl, e de sua respectiva tradução, A Fantástica Fábrica de Chocolate (2014), realizada por Dulce H. Vainer, deparamo-nos, ao final de alguns capítulos, com as canções dos Oompa-Loompas sobre os incidentes que ocorrem com os personagens infantis da obra. Podemos entender que essas canções têm como objetivo realizar uma reflexão sobre o personagem e sobre o que o levou a essa trágica situação. Consideramo-las como uma lição de moral, característica das histórias infantis, que refletem sobre o mau comportamento, aquele que não deve servir de exemplo nem ser seguido pelo público-alvo da obra: as crianças. 
Quadro 12 - Trechos com canções dos Oompa-Loompa(s) no TO e no TT

\begin{tabular}{|c|c|}
\hline $\begin{array}{l}\text { 'Augustus Gloop! Augustus Gloop! } \\
\text { The great big greedy nincompoop! } \\
\text { How long could we allow this beast } \\
\text { To gorge and guzzle, feed and feast } \\
\text { On everything he wanted to? } \\
\text { Great Scott! It simply wouldn't do! } \\
\text { However long this pig might live, } \\
\text { We're positive he'd never give } \\
\text { Even the smallest bit of fun } \\
\text { Or happiness to anyone. } \\
\text { So what we do in cases such } \\
\text { As this, we use the gentle touch, } \\
\text { And carefully we take the brat } \\
\text { And turn him into something that } \\
\text { Will give great pleasure to us all - } \\
\text { A doll, for instance, or a ball, } \\
\text { Or marbles or a rocking horse. } \\
\text { But this revolting boy, of course, } \\
\text { Was so unutterably vile, } \\
\text { So greedy, foul, and infantile, } \\
\text { He left a most disgusting taste } \\
\text { Inside our mouths, and so in haste } \\
\text { We chose a thing that, come what may, } \\
\text { Would take the nasty taste away. } \\
\text { "Come on!" we cried. "The time is ripe } \\
\text { To send him shooting up the pipe! } \\
\text { He has to go! It has to be!" } \\
\text { And very soon, he's going to see } \\
\text { Inside the room to which he's gone } \\
\text { Some funny things are going on. }\end{array}$ & $\begin{array}{l}\text { Augusto-gusto! Augusto-gusto! } \\
\text { É olhar pra ele e morrer de susto! } \\
\text { Pão, requeijão, bala, macarrão, } \\
\text { Só pensa em comer o gordo bobão. } \\
\text { Não dá sossego, tudo ele quer, } \\
\text { Por todo canto ele mete a colher. } \\
\text { Não sabe cantar, não sabe sorrir, } \\
\text { Sua vida é só mastigar e engolir. } \\
\text { Menino mais chato, pessoa xinfrim! } \\
\text { O que fazer em casos assim? } \\
\text { A gente podia estalar o dedo } \\
\text { E fazer Augusto virar brinquedo! } \\
\text { Bola de gude, pião, peteca, } \\
\text { Jogo de damas, balão, boneca. } \\
\text { Mas desse menino tão mal-humorado } \\
\text { Só ia sair brinquedo quebrado. } \\
\text { E se o Augusto, minha gente, } \\
\text { Virasse um tubo de pasta de dente? } \\
\text { Mas pasta de dente tem gosto de menta, } \\
\text { E o gosto do Augusto ninguém aguenta! } \\
\text { Mudar de verdade esse paspalho } \\
\text { Vai dar mesmo muito trabalho } \\
\text { Pra adoçar esse humor tacanho } \\
\text { A primeira coisa vai ser um banho } \\
\text { Mas não pensem vocês que vai ser de chuveiro } \\
\text { O Augusto vai entrar de corpo inteiro } \\
\text { Num rio de calda de chocolate. } \\
\text { Depois então é bate-que-bate, } \\
\text { Põe creme, enrola e põe cobertura } \\
\text { Que tem de secar até ficar dura. } \\
\text { Esta receita é pra fazer bombom fino, } \\
\text { Mas não sei se dá certo bombom de menino. } \\
\text { É um bom tratamento, sem crueldade, } \\
\text { Ninguém está a fim de fazer maldade. } \\
\text { O Augusto é fogo, haja paciência! } \\
\text { Mas não é caso pra agir com violência. } \\
\text { Então não se assustem, não tenham medo. } \\
\text { Só queremos um Augusto menos azedo. }\end{array}$ \\
\hline
\end{tabular}

Fonte: elaborado pelas autoras. 
As duas canções falam sobre a mesma criança, Augustus Gloop/"Augusto Glupe”, aparecem no final do capítulo "Augustus Gloop goes up the Pipe"/“Augusto Glupe entra pelo cano" e fazem uma reflexão acerca do que aconteceu com o personagem: o menino, que estava estendido na grama, se debruçou para alcançar o rio de chocolate e beber a calda diretamente do rio, ignorando os apelos de Wonka para que se afastasse e os gritos de seus pais avisando que estava se debruçando demais. Como resultado, o menino caiu e afundou, sendo sugado por um dos canos suspensos.

Ao colocarmos as canções lado a lado, podemos observar que o conteúdo de ambas é diferente. Na primeira canção, podemos perceber o desprezo dos Oompa-Loompas quanto ao personagem, pois, quando se referem ao menino, utilizam palavras como beast, pig, brat, revolting boy, greedy e foul, que, se fossem traduzidas fielmente - "besta", "porco", "pirralho", "garoto revoltante", "guloso" e "imundo" - deixariam a canção com um conteúdo passível de não ser aceito pelos adultos na cultura de chegada, e a história, consequentemente, poderia não ser compartilhada com o público-alvo, uma vez que os adultos são responsáveis por partilhar a mensagem. Com um esquema de rimas bem planejado, sonoridade convidativa e ritmo constante, nós conseguimos entender que essa indisposição com relação ao garoto ocorre devido ao seu comportamento, à sua gula, pois reflete o sentimento que desenvolvemos pelo personagem; logo, concordamos que os atos de Augustus Gloop não devem ser tomados como exemplo, mas, para nós, a tradução desses vocábulos não soa como outro modelo a ser seguido. Assim, podemos perceber o motivo de alguns adultos não gostarem das obras infantis de Roald Dahl: a escolha do seu vocabulário, em alguns pontos, pode agradar o público infantil, mas não agrada os pais desse público, que pode considerá-lo impróprio.

Do outro lado do quadro, temos a canção presente no TT e que pouco se relaciona com a do TO. Como as palavras, já mencionadas, poderiam não ser bem-vistas na tradução, e as rimas se perderiam durante o ato tradutório, Dulce H. Vainer criou novas canções que se enquadram naquilo que nos é familiar, a partir de expressões e frases conhecidas; temos, neste caso, uma canção mais extensa do que a original, com seu próprio esquema de rimas, que conta, também, com sua própria sonoridade e seu próprio ritmo, conseguindo atingir o mesmo objetivo da canção do TO: mostrar que o comportamento do personagem não é um exemplo a ser seguido.

Entendemos que a escolha de Roald Dahl por essas novas criaturas foi para afastar a obra ainda mais do comum: se colocasse na história homens e mulheres comuns como funcionários da fábrica, talvez as inovações e a magia não fossem tantas, devido ao ceticismo e à ganância do ser humano, como explica logo no início da história. Assim, ao colocar esses 
novos homenzinhos, ele demonstra que, ali dentro da fábrica, tudo é possível de acontecer.

\section{Considerações finais}

Propomo-nos, no início do trabalho, analisar o léxico de maior frequência da obra original, Charlie and the Chocolate Factory (2007), e da obra traduzida $A$ Fantástica Fábrica de Chocolate (2014), com a finalidade de entender como as escolhas do autor, Roald Dahl, e da tradutora, Dulce H. Vainer, influenciaram na construção do gênero literário infantil e fantástico a partir do conjunto vocabular mágico e das canções dos Oompa-Loompas, que explicitam as concepções de moralidades e se enquadram na característica das histórias infantis.

Com base nesses objetivos e nos fundamentos da Linguística de Corpus, dos Estudos da Tradução Baseados em Corpus e da Lexicologia, apontados ao longo do trabalho, bem como com o uso do software WordSmith Tools, chegamos ao que consideramos o conjunto lexical que traz à baila a fantasia na obra e que se relaciona diretamente na composição de uma interpretação mágica pelos leitores, a saber: Wonka é um dos personagens principais e o criador da fantasia, tendo em vista que toda a magia existente no livro é originária de suas ideias e criações; Charlie é o herói da história, o menino bom que consegue o prêmio final; o chocolate é o objeto de fascínio, que une todos os personagens; factory/“fábrica" é o lugar em que a fantasia acontece, é onde o cotidiano, os problemas são deixados de lado e se é apresentado a invenções e criações que estimulam os imaginários infantil e, até mesmo, adulto; e os Oompa-Loompas/ "Umpa-Lumpas" são os ajudantes na missão de Wonka, que trazem a moral acerca dos comportamentos que não devem ser tidos como exemplo.

Refletimos, também, sobre as escolhas tradutórias, uma vez que ao longo da obra traduzida foram realizadas substituições de nomes/palavras por sinônimos e pronomes e omissões de sujeito, a fim de que a tradução não se tornasse repetitiva/cansativa, mas com um ritmo que prendesse a atenção do leitor. A tradutora simplificou, também, a escrita dos nomes dos personagens, mas manteve a sonoridade dessas nomenclaturas; recriou as canções dos "Umpa-Lumpas", diferenciando-as das da obra original; e trouxe as éticas acerca das condutas dos personagens a partir de palavras e elementos que são conhecidos de seu público-alvo.

Entendemos que a perspectiva de corpus pode amparar os tradutores de obras de cunho infantil e fantástico, auxiliando-os nas escolhas lexicais que possam ser mais adequadas às atribuições da Literatura voltada às crianças. Além disso, o instrumental e as prerrogativas linguísticas favorecem a leitura dos itens de maior frequência, permitindo reconhecer sua influência e o impacto de seus usos em contexto. 
Por fim, acrescemos que, embora a Linguística de Corpus e os Estudos da Tradução Baseados em Corpus vigorem há duas décadas entre os principais estudos sobre linguagem e tradução, sua influência pode estender-se às práticas atuais e apontar novos caminhos, articulando-se com a análise literária, conforme procuramos mostrar em nossa breve investigação da obra de Dahl.

\section{The translations of Roald Dahl's fantastic world: a study based on the corpus of the work Charlie and the Chocolate Factory}

\begin{abstract}
The main purpose of this paper is to analyze the translation into Portuguese of the work Charlie and the Chocolate Factory (2007), written by Roald Dahl, considering the lexicon related to Fantastic Children's Literature. In order to perform the research, we used Children's Literature theories (COELHO, 1991, 2000) and Fantastic Literature basis (TODOROV, 1975; HELD, 1980), as well as Lexicology (BIDERMAN, 1987), Corpus Linguistics (BERBER SARDINHA, 2000) and Corpus Based Translation Studies (BAKER, 1993, 1996; CAMARGO, 2005, 2007). We also compared the Target Text (TT) and the Source Text (ST) by using WordSmith Tools software, with the objective of identifying frequency and concordance of lexical items which are common in Dahl's writings and take up characteristics of a magical world. Therefore, we outlined paths to verify this kind
\end{abstract}

of Fantastic vocabulary in Source and Target Languages, emphasizing the way it conceives the idea of marvelous to children audience.

Keywords: Corpus Based Translation Studies. Corpus Linguistics. Fantastic Children's Literature. Roald Dahl.

\section{Nota}

1 O léxico é a lista de itens lexicais (e suas propriedades idiossincráticas) que uma dada língua possui. De acordo com Chomsky (1995), um item lexical é formado por traços semânticos, fonológicos e formais. Traços semânticos são relevantes para a interface com o sistema conceitual-intencional. Traços fonológicos são relevantes para o sistema articulatório-perceptual e só são acessíveis depois de Spell-out. Traços formais são acessíveis ao sistema computacional e mostram diferenças cruciais que são refletidas na derivação.

\section{Referências}

BAKER, M. Corpus Linguistics and Translation Studies: implications and applications. In: BAKER, M.; FRANCIS, G.; TOGNINI-BONELLI, E. (Ed.) Text and technology: in honour of John Sinclair. Amsterdã: Jonh Benjamins, 1993. p. 233-250.

Corpus-based Translation Studies: the challenges that lie ahead. In: SOMERS, H. (Ed.) Terminology, LSP and translation studies in language engineering: in honour of Juan C. Sager. Amsterdã: John Benjamins, 1996. p. 177-186.

BERBER SARDINHA, T. Linguística de corpus: histórico e problemática. Delta: documentação de estudos em linguística teórica e aplicada, São Paulo, v. 16, n. 2, p. 323-367, 2000.

Linguística de corpus. São Paulo: Manole, 2004. 
BIDERMAN, M. T. C. A estruturação do léxico e a organização do conhecimento. Letras de hoje, v. 22, n. 4, p. 81-96, 1987. Disponível em: $<$ http://revistaseletronicas.pucrs.br/ojs/index. php/fale/article/view/17049/11065>. Acesso em: 28 jun. 2016.

BETTELHEIM, B. A psicanálise dos contos de fadas. Tradução de Arlene Caetano. 16. ed. Rio de Janeiro: Paz e Terra, 2002.

CAMARGO, D. C. Padrões de estilo de tradutores: um estudo de semelhanças e diferenças em corpora de traduções literárias, especializadas e juramentadas. 2005. $512 \mathrm{f}$. Tese (Livre-Docência em Estudos da Tradução) - UNESP/ IBILCE, São José do Rio Preto, 2005.

Metodologia de pesquisa em tradução e linguística de corpus. São Paulo: Cultura Acadêmica; São José do Rio Preto: Laboratório Editorial, 2007. (Coleção Brochuras, v. 1. 65 p.).

CHOMSKY, N. Language and nature. Mind, v. 104, n. 413, p. 1-61, 1995.

COALLA, F. S. Lo fantástico en la obra de Adolfo Bioy Casares. Estado de México: Universidad Autónoma del Estado de México, 1994. (Colección Lecturas Críticas, 18).

COELHO, N. N. Literatura infantil: teoria, análise, didática. São Paulo: Moderna, 2000.

. Panorama histórico da literatura infantil/juvenil: das origens Indo-Européias ao Brasil contemporâneo. 4. ed. São Paulo: Ática, 1991.

DAHL, R. Charlie and the chocolate factory. New York: Puffin Books, 2007.

. A fantástica fábrica de chocolate. Tradução de Dulce H. Vainer. 5. ed. São Paulo: Martins Fontes, 2014.

HELD, J. O imaginário no poder: as crianças e a literatura fantástica. São Paulo: Summus Editorial, 1980.

QUEIROGA, M. G. de; FERNANDES, L. P. Translation of Children's Literature. Cadernos de Tradução, v. 36, n. 1, p. 62-78, 2016.
SCOTT, M. WordSmith tools version 6. Liverpool: Lexical Analysis Software, 2015.

TODOROV, T. Introdução à literatura fantástica. São Paulo: Perspectiva, 1975. 